\title{
Notes on the Tables for Gaussian Quadrature of N. M. Steen, G. D. Byrne and E. M. Gelbard
}

Editorial Remark. Tables for $n$-point Gaussian quadrature of

$$
\int_{0}^{\infty} \exp \left(-x^{2}\right) f(x) d x
$$

with $n=1(1) 8$, have been published previously by Ben HuANG \& Don P. Giddens "A new table for a modified (half-range) Gauss-Hermite quadrature with an evaluation of the integral $\int_{0}^{\infty} \exp \left(-u^{2}-x / u\right) d u, " J$. Math. and Phys., v. 47, 1968, pp. 213-218. Although their precision is 9-10 significant digits, comparison with the present Table II shows agreement to only 3-4 significant digits or less, when $n=8$. Another set of tables by Dr. M. R. Pine with $n=1(1) 10$, which was received by the editors independently, and recomputation by one of the editors, both seem to confirm the accuracy of Table II to at least 12 significant digits in the range $1 \leqq n \leqq 10$. Furthermore, Dr. Pine checked the tables of Steen, Byrne and Gelbard. His report follows:

\section{Note by Milton R. Pine}

At about the same time that the preceding paper was submitted for publication, I submitted a set of tables on Gaussian-Quadrature for $\int_{0}^{\infty} f(x) \exp \left(-x^{2}\right) d x$ up to $n=10$. I used two methods for getting the set of orthogonal polynomials on the desired interval, one a recursion relation for the polynomials and also an orthogonalization procedure. Both of these methods lose significance rapidly.

The editor sent to me the tables of Steen et al. Their tables agree with mine up to the point where I have confidence in the number of significant digits preserved. Using Steen's tables, I have found that they integrate correctly to better than fourteen decimal places, the monomials up to order $2 n-1$. This is all one can expect from a quadrature scheme starting with 15 significant figures.

Computer Applications Incorporated

555 Madison Avenue

New York, N. Y. 10022

Received May 23, 1968. 